Max-Planck-Institut für demografische Forschung

Max Planck Institute for Demographic Research

Doberaner Strasse 114 - D-18057 Rostock · GERMANY

Tel +49 (0) 3812081 - 0; Fax +49 (0) 3812081 - 202;

http://www.demogr.mpg.de

MPIDR WORKING PAPER WP 2001-005

FEBRUARY 2001

Measure and dynamics of marriage

squeezes: from baby boom to baby bust

in Italy

Romina Fraboni (fraboni@istat.it)

Francesco C. Billari (billari@demogr.mpg.de)

(C) Copyright is held by the authors.

Working papers of the Max Planck Institute for Demographic Research receive only limited review. Views or opinions expressed in working papers are attributable to the authors and do not necessarily reflect those of the Institute. 


\title{
Measure and dynamics of marriage squeezes: from baby boom to baby bust in Italy
}

\author{
Romina Fraboni \\ Istituto Nazionale di Statistica (ISTAT) \\ Via Ravà 150, 00142 Roma, Italy \\ e-mail: fraboni@istat.it \\ Francesco C. Billari \\ Max Planck Institute for Demographic Research \\ Doberaner Str. 114, D-18057 Rostock, Germany \\ e-mail: billari@demogr.mpg.de
}

\begin{abstract}
Significant changes in the propensity to marry, together with baby booms, busts and migrations shape the marriage market. Big changes in the level of fertility may affect, some decades later, the opportunities of marriage of eligible individuals, creating a marriage squeeze. Italy provides an interesting case study because since World War II, it has been characterised by alternate periods of declines and rises of the annual number of births and by their differential patterns between regions. In this paper we study the dynamics of the Italian marriage market (years 1969-1995) by using some indexes proposed by Schoen as well as two additional measures. The results of regional analysis
\end{abstract}


also suggest that marriage squeeze has also been shaped by internal migratory movements.

The recent and prolonged phase of steep fertility decline in Italy, together with the drop of interregional movements, suggests the possibility of a perspective increasing disadvantage of men in the marriage market.

Keywords: marriage squeeze, marriage market, nuptiality tables, fertility fluctuations, Italy.

\section{Introduction}

We do not usually like to think of ourselves as participants in a market when it comes to personal aspects of life such as the search for a partner. Being compared to other individuals who compete for the same possibly scarce commodity does not seem represent a comforting idea. This is connected to the fact that, in contemporary western societies, the family sphere is viewed as being something theoretically quite different from the economic market, because of the strong roots of concept such as romantic love and parental love. A market approach to marriage has been adopted for a long time by economists (e.g. Becker, 1974 [2], 1981[3]) to explain why people do get married or remain single, how do they live a married life, and the frequency and causes of divorce. Nevertheless, in the literature there is not widespread agreement on what a marriage market is, given that each discipline tries to focus on some of its more relevant aspects. For what we need here, the marriage market is, broadly speaking, the place of interaction between the sexes at the moment of the search for a partner: there, each individual neither represent a pure object nor a pure acquirent, but he/she plays both 
roles a double choice, double consent must be verified (Becker, 1974 [2]).

Assortative mating, mate selection and partner selection (Girard, 1981 [19]) are the most used terms to indicate the process of choice of the partner. Trying to trace the boundaries of the place where such process develops is very difficult and, after all it would not be very useful. In fact, a unique "space" called the marriage market simply does not exist as the search for a partner involves several dimensions of our life: school, university, place of work, place of living, neighbourhood, friends, family, relatives, cultural associations, sporting club, religious and political associations, place of holidays, etc. All these represent a potential marriage market: some of them may play a more important role than others, not only because of our greater involvement in terms of time, but also because of the higher value which we recognise or attribute to them, and which is the result of internalised norms ${ }^{1}$. Bozon and Heran (1988[8]) distinguish among three main kind of places of meeting: public places, open to everybody; reserved places, pretty heterogeneous, but for which the admission depends on the payment of a fee or some other form of selection; private places which mainly include family and friends. Henry (1973[29]), on the one hand, compares the relations between the sexes to the market where the bargaining and the exchange happens and, on the other hand, to the retort, the tool where chemical reaction between certain proportions of atoms of different elements may occur ${ }^{2}$. Nevertheless

\footnotetext{
${ }^{1}$ People develop a preference for certain spaces more than others also as a result of the segmentation of the social structure: judgement categories are strongly related to interiorised categories of perceptions, which differ according to sex and social milieu (Bozon, $1991[7])$.

${ }^{2}$ Henry analyses the way in which two populations, composed by single individuals of each sex (atoms), sort and give birth to a new population composed by couples (molecules). Molecules take form when certain proportion of atoms meet (Henry, 1973[29]).
} 
it is not enough to have just the same number of partners of both sexes to give birth to new partnerships for everybody. Partnership formation is a more complicated process which does not reduce itself to passages from status of being single to married. Henry suggests a broader concept besides that of market, as this not necessarily means binding relations. The process of couple formation is characterised by a sequence of steps. Joining a group, a 'circle of relations', on the basis of the age of those who belongs to that group, is one of these steps. There are multiple circles according to the geographical dispersion of a population and each of them combine some particular ages of its individuals. Henry (1972[28]) hypothesises that individuals choose to fit a certain circle on the basis of their age, but then the choice of the mate inside each circle of relations is made randomly.

Distance may represent a significant constraint to find a suitable part$n^{3}{ }^{3}$. During the twentieth century the improved communication among countries and the rapidity of their diffusion has been so high to produce a greater mobility of the people on the territory, besides a greater social mobility, also reflected on the process of assortative mating .

Strictly related to the idea of a marriage market is the concept of mar-

\footnotetext{
${ }^{3}$ People used to live in small communities where the number of available mates was quite limited and often further diminished by societal rules (due to the organisation of the society in caste or class, for example)(Hajnal, 1965[27]). This affected the possibility of getting married by restricting the circle of potential mates. To counteract this, societies reacted in different ways. For example Eastern European Jewish community had recourse to the professional 'marriage brokers'; in a system based on caste the solution mainly meant finding a mate outside the local community, thus promoting intermarriage with all the relevant effects on the social organisation and genetic structure of the population. Moreover, marriage was used as a tool of 'alliance' between families, kinship, communities, and countries, especially by well-to-do classes and the aristocracy.
} 
riage squeeze. The term was introduced by Glick et al. (1963 [22] quoted by Glick, 1988 [21]). As many demographic, biological, social and economic factors influence nuptiality, they can sometimes cause a 'squeeze' on the marriage market and on the possible choices of people involved. We will refer to this phenomenon here as an imbalance in the marriage market. Indeed this expression was introduced to refer to the effect of the baby boom: girls born during the rapid increase in the birth rate eventually faced a shortage of men born few years early. Glick et al. (1963 [22]) maintained that the shortage of eligible men placed women in a marriage squeeze. Many scholars studied a way to measure this squeeze (Akers, 1967 [1]; Musham, 1974 [41]; Schoen, 1981 [43], 1982 [44], 1983 [45]), or to measure its causes and effects (Heer and Grossbard-Shechtman, 1981 [30]; Caldwell et al., 1983 [9]; Goldman et al. 1984 [23]; Greene and Rao, 1995 [25] $)^{4}$. The general idea is that the number of eligible men relative to that of eligible women is to be taken into account as one of the factors that influence decisions to get married or remain single. For example, when at an aggregate level more men are available for a given number of women ${ }^{5}$ the number of women who marry increases. Moreover, the imbalance between the sexes, measured in terms of the sex ratios, has been linked to the spread of cohabitation and divorce (Grossbard-Shechtman, 1985 [26]). From a demographic point of view, the marriage squeeze has generally been studied in relation to the variation in the age-sex composition due to fluctuations in fertility trends (Akers, 1967 [1]; Schoen, 1981 [43], 1983 [45]). This sheds light on the 'quantitative' features of a population. In addition, many attempts have been made to evaluate the

\footnotetext{
${ }^{4}$ For a review of the literature see also McDonald, 1995 [38].

${ }^{5}$ That is to say: there is a shift in the aggregate demand, while the aggregate supply remains unchanged.
} 
'qualitative' characteristics of local marriage markets in assortative mating and marital dissolution ${ }^{6}$.

In contemporary Europe, fluctuations in fertility caused by baby booms and baby busts gave rise to very important changes in the number of live births at the national level. And in many countries internal migration, immigration, and emigration have shaped the size of the eligible population in significant ways. It is conceivable that large fluctuations had a significant impact on the marriage market, creating marriage squeezes, and they may also have been partially responsible for changes in the transition to marriage. There has however not been any systematic attempt to analyse the dynamics of the marriage market and marriage squeezes in the light of long-term fluctuations in birth rates. Despite the richness of the topic and its strong link to other demographic phenomena (fertility, union formation, migration), the marriage squeeze and its dynamics have not received much attention in Europe. Most of the contributions in this field of research come from American studies of the causes and consequences of the marriage squeeze, especially in the context of local areas.

In this paper we focus on how to measure marriage squeezes from a dynamic perspective. We evaluate the systems of measurement used in the literature and adopt the two-sex approach advocated by Schoen. We also propose to accompany Schoen's indicies by two simple indices with a similar meaning. We then focus our analysis on the Italian marriage market since World War II. We study Italy both in its baby-boom period and its baby-

\footnotetext{
${ }^{6}$ There is some evidence that increased education and labor force participation among unmarried women and high geographic mobility rates in local areas also increase marital instability and lower nonmarital fertility (South and Lloyd, 1992 [48], 1995 [49]).
} 
bust period. The latter is particularly interesting because it made Italy one of the countries with the lowest fertility ever observed. The analysis is conducted both at the national and at the regional level. The regional-level analysis also allows us to present a tentative interpretation of the role of internal migrations.

The paper is structured as follows. In Section 2, we critically review and discuss existing measures of the marriage squeeze, and we introduce two simple new ones. In Section 3, we analyse the dynamics of the marriage squeeze both at the national and the regional level. In Section 4 we present some hypotheses on the role of differential mobility between regions and the consequences thereof for the marriage market.

\section{Measuring marriage market imbalances}

The measures introduced in the literature for studying marriage market conditions can be broadly divided between two categories: those that use sex-ratios and those that focus on the two-sex approach. Let us first discuss both sets of measures and then propose two simple new measures.

\subsection{Measures based on sex ratios}

The most common way to measure the marriage squeeze is by means of a sex ratio. This is usually expressed as the number of eligible men for every 100 eligible women.

A very simple measure of the marriage market is the sex ratio for selected age groups determined on the basis of cross-classified ages at marriage for men and women. Often, men in a given age group are compared to women in a smaller group that is some years younger. Of course, having age groups 
of the same width does not take into account the fact that the female age distribution of marriage is normally more concentrated around the mode than the male distribution and that there may be variations in the timing of the process.

Akers (1967[1]) defines an index of the marriage squeeze as a weighted ratio of men who marry women aged $y$ over women aged $y$, where the weights at each age approximate the probability of marriage at that age. The weights for the index proposed by Akers are first marriages of women aged 15-24 and men aged 15-29. According to Akers, these ranges include those ages at which most women marry and the ages of most of the men whom they marry (more than 80\% in both cases, Akers, 1967 [1]). He attributes the increase in the age at marriage and in marriage rates observed in United States in the 1960s to the dynamics of the age-sex composition of the population. The disproportion in the number of males and females of a given age at their first marriage were due to the fact that more females were born in the baby-boom period (after World War II: June 1946 - July 1947) than males a few years earlier (July 1944 - June 1945). As a consequence, American women in the 1960s faced a marriage squeeze. It should be noted that the age groups to which the index refers do not take into account a high proportion of current marriages.

To measure the impact on sex roles in the United States of the female marriage squeeze (the shift in the sex ratio at eligible ages which took place in the late 1950s and early 1960s), the contraceptive revolution (which began in the 1960s), and the women's liberation movement Heer and GrossbardShechtman (1981[30]) introduce two different indexes. Their basic idea is to compare men and women in an age interval of the same width for both sexes. In particular, the age intervals were chosen such that the midpoint 
of the male group, 23.0 years, was very close to the median age at first marriage for men during the period that starts in the early 1960s and ends in 1975; while the midpoint of the female group, 20.5 years, was very close to that of women at the beginning of this period. Moreover, they also suggest taking into account those who are not yet married by introducing the ratio between unmarried men in the age-group 20-29 to unmarried women in the age-group 18-29 (Heer and Grossbard-Shechtman, 1981 [30]). In such cases, the index assumes an equilibrium value of one. For both of these definitions they observe the existence of a marriage squeeze for women in the United States for the period under study.

Goldman et al. (1984[23]) criticise sex ratios because they do not offer a realistic measure of the pool of eligible partners and, alternatively, they suggest that one should develop a measure of the availability of potential mates. The so called Availability Ratio incorporates information about both the available pool and the competition for that pool. This reflects normative selection patterns by some given characteristics (such as race, age, education in their empirical study). More precisely, they define the Availability Ratio for a woman (say Ego) as the ratio between the number of suitable men (for that woman) and the average number of suitable women for (the woman's) suitable men. The $A R$ for a man or a cohort is, in turn, simply defined as the number of suitable women divided by the average number of suitable men for these women. One should also note that the $A R$ is not the probability of Ego's marrying. Yet, the $A R$ for a woman, gives us some sense of how likely Ego is to find a mate or the odds that Ego could marry if other considerations were conducive to marriage ${ }^{7}$. Again we have the following

\footnotetext{
${ }^{7}$ The index requires the specification of the concept "suitability" so as to arrive at a measure of the average number of suitable women for suitable men (the denominator of the
} 
situation: if the average woman in the original cohort has one suitable man and the average suitable man has one suitable woman, then $A R=1$. In addition to the $A R$, Goldman et al. introduce the Comparative Odds Ratio $(C O R)$. This index is obtained by dividing the male availability ratio by the availability ratio for women of the same race, age, and educational level. Thus, the COR expresses how much better or worse the market chances are for men and women with selected characteristics, such as the same race, age, and education.

The $A R$ and $C O R$ have been applied to the Italian case (De Rose e Rufo, 1994[14]) in an analysis of the Italian population distributions by sex and marital status in various censuses (years 1936-1981). They obtain two major results, and it is useful to summarise them briefly in view of our application. First, there is a general disadvantage for women at most ages if one excludes the age-group15-19. Second, the cohorts of women born during the two world wars and during the baby-boom are in a better position on the marriage market than other women in the same period. Moreover, under the assumptions that widowed and divorced people choose their partners among their own, the position of these women in the marriage market is even worse, because of the high sex mortality ratio at older ages. The analysis of the $C O R$ ratio shows mainly the same results: a better position for women only up to age 20 , when the marriage market then becomes disadvantageous for them (the number of single men available for single women decreases $A R$ for a woman). Goldman and her coauthors calculate this for women of particular ages (thus selecting a cohort) referring to men over all ages but with, e.g., the same education and race (assuming homogamous partner choice). The competition is given by the total number of suitable men for the chosen cohort of women divided by the average number of suitable women for these men. 
progressively) after that age. Only for the 1981 census does there emerge a favourable situation for women older than 40. The authors also note that, over time, the marriage market conditions for single women at older ages improve as the rates, even if still negative, become closer to 100. The 1981 situation is new, as we observe a rise of the $C O R$ ratio at older ages (which means improving conditions for women at older ages): it assumes the shape of a reversed J.

There are, however, some drawbacks to the measures we have just discussed. First of all, the assumption that most partnerships are established within a given age range or with a given age difference between partners does not provide the desired flexibility for measuring the marriage squeeze we are looking for. This is a key aspect, especially when analyses are conducted over a longer time span. In fact, not only the timing of marriage for men and women may change over time, but also the age preferences of each partner may shift. Moreover, these measures exclude factors other than age - and sometimes marital status - for defining the marriage market. Obviously, many other social, economic, cultural, and personal factors should enter into the definition of availability. Lastly, most existing ratios consider only cohorts in their early twenties, thereby ignoring the question of availability for older unmarried cohorts, which are becoming an increasingly larger percentage of the unmarried pool. Schoen (1988[46]) observes, among others, that sex ratios only capture one-sex compositional effects. Even when refined, sex ratios combine changes in the age- and sex-specific rates with one-sex compositional effects (marginal effects). To measure the marriage squeeze, however, it would be necessary to measure the changes in age- and sex-specific marriage rates which are produced by changes in 
the age and sex composition of the population. Furthermore, such indices are adequate for the analysis of the Italian case. After a slight anticipation in age at marriage in the early 1960s, marriage timing in Italy moved in the direction of higher ages at first marriage and increasing variability at the regional level (De Sandre et al., 1997[15]). Moreover the dispersion of the age distribution around the modal value is normally higher in the male pattern than in the female one, so that fixing the age range would exclude different proportions of marriages.

\subsection{Schoen's index: a measure derived from two-sex nuptial- ity tables}

Several solutions to the so-called two-sex problem (that is, the reconciliation of male and female rates) have been proposed in the literature. Two main families of models can be envisaged: the axiomatic approach, which starts from a list of 'axioms' have been set as a requirement for an acceptable solution (Hoem 1969[31], Pollard 1975 [42], Schoen 1983[45]) and the behavioural approach, which starts from a set of assumptions about the individual behaviour of candidates searching for a partner (Henry 1972[28], Dagsvik 1998[12]). Some are based on the geometric, arithmetic, or harmonic mean between the male and the female rates, others on the minimum or maximum solution (they assume, for instance, the number of marriages to be the minimum number obtained by multiplying the sex-specific rate by the corresponding population). The main alternative approaches to the harmonic mean solution are the iterative adjustment (McFarland, 1975[39]) and the panmitic circles approach (Henry, 1972[28]). For a comparative analysis see Schoen (1988[47]) and Keilman (1998[36]). 
Schoen [45] provides a formal definition of marriage squeeze. He considers the marriage squeeze to be closely associated with the 'two-sex problem' in formal demography, and he provides a harmonic mean consistency condition as the basis for measuring it. The consistency condition is aimed at reconciling male and female rates. Schoen specifies and then calculates twosex life table models that reflect the complex interactions of the observed marriage market. The basic idea is to start from a rectangular population, in which the number of people is the same at every age. In this population there is no marriage squeeze, as the population at risk for every age is the same for both sexes. Period and cohort experience are identical and, if marriage preferences are fixed, the number of males who marry in any given birth cohort must be the same as the number of females who marry. Schoen then adds the following assumptions:

1) There is no mortality between the ages of 15 and 49 . The only decrement of the table is marriage. This is a fairly realistic assumption in developed countries;

2) The male and female radix values in the table are equal: ${ }^{m} l_{0}={ }^{f} l_{0}$ are the initial cohort sizes. Even though the sex ratio at birth is around 105 males for every 100 females, this assumption preserves the symmetry and balance of the two sexes, and it greatly simplifies the calculations.

The experience of each cohort in the model is the same as the experience of the entire population in any given year. The number of males and females who marry in any given period (or cohort) is indicated by ${ }^{m f} l_{0}^{w}$, where $l_{0}^{w}$ is the number of marriages to persons at age above 0 , and the superscript 
$m f$ indicates that the value is from a two-sex (male-female) table. The analogous values from a one-sex male and female life table are ${ }^{m} l_{0}^{w}$ and ${ }^{f} l_{0}^{w}$ : they are constructed using the same values ${ }^{f} l_{0}={ }^{m} l_{0}$, and they reflect the observed male and female rates in a given population ${ }^{8}$.

Therefore, under a specified set of marriage preferences, ${ }^{m f} l_{0}^{w}$ gives the number of males and females who marry in a population free of any marriage squeeze. Under the same set of marriage preferences, but using the rates which bear the imprint of the age-sex compositional effects that produce the marriage squeeze, ${ }^{m} l_{0}^{w}$ and ${ }^{f} l_{0}^{w}$ are the number of males and females who marry.

Schoen's index for measuring the marriage squeeze is then defined as:

$$
S=\frac{{ }^{m} l_{0}^{w}-{ }^{f} l_{0}^{w}}{{ }^{m f} l_{0}^{w}}
$$

which expresses the difference between the number of male and female lifetable marriages calculated using rates that bear the imprint of the marriage squeeze, divided by the number of either the male or female life-table marriages in a model that has the same set of magnitudes of the marriage attraction but no marriage squeeze. Equation (1) describes the magnitude and the direction of a marriage squeeze as follows:

- when both one-sex models have the same number of marriages, i.e., ${ }^{m} l_{0}^{w}={ }^{f} l_{0}^{w}$, then $S=0 ;$

\footnotetext{
${ }^{8}$ In fact, observed male age-specific marriage rates can be used to calculate a one-sex male life table, with ${ }^{m} l_{0}^{w}$ males marrying out of a cohort of ${ }^{m} l_{0}$. Similarly, for females, we can construct a set of age-specific marriage rates, with ${ }^{f} l_{0}^{w}$ females marrying out of a cohort of ${ }^{f} l_{0}$. The marriage schedule implied by the observed male and female rates (under a specified set of marriage preferences) yields what has been called a TWONUP model, where ${ }^{m f} l_{0}^{w}$ males and ${ }^{m f} l_{0}^{w}$ females marry out of a cohort of $l_{0}$ persons of each sex, in a population free of any marriage squeeze.
} 
- when male rates yield a number of marriages greater than the number of female marriages, ${ }^{m} l_{0}^{w}>{ }^{f} l_{0}^{w}$, then $S>0$, and there is a marriage squeeze for females;

- when male rates yield a number of marriages smaller than the number of female marriages, ${ }^{m} l_{0}^{w}<{ }^{f} l_{0}^{w}$, then $S<0$, and there is a marriage squeeze for males.

The higher the absolute value of $S$, the tighter the squeeze. Schoen proposes also a measure of the degree to which the age-sex composition of the given population serves to depress the observed number of marriages below what would have resulted in the absence of an imbalance between the sexes, as well as the number of marriages 'lost' to the marriage squeeze as a fraction of the number of observed marriages. In particular, Schoen suggests using also the following two indices:

$$
\begin{gathered}
R=\frac{{ }^{m} l_{0}^{w}+{ }^{f} l_{0}^{w}}{2^{m f} l_{0}^{w}} \\
Q=\frac{1-R}{R}=\frac{2^{m f} l_{0}^{w}-\left({ }^{m} l_{0}^{w}+{ }^{f} l_{0}^{w}\right)}{{ }^{m} l_{0}^{w}+{ }^{f} l_{0}^{w}}
\end{gathered}
$$

Schoen proves that, by taking into account the proportion of male and female life-table cohorts that never marry $(\beta$ and $\gamma$ ), it is possible to arrive easily at a different expression of the marriage squeeze index (1).

$$
S=\frac{\gamma-\beta}{1-\sqrt{\gamma \beta}}
$$

The formulation contained in equation (4) is very useful from a practical point of view because it shows that, under mild assumptions, we only need to know the two parameters $\gamma$ and $\beta$, which are simple functions of the sum of the observed age-specific male and female marriage rates, to compute Schoen's index of the marriage squeeze. 
Before moving on, it is worth noting that Schoen's approach analyses the dynamics of the interactions between the sexes in nuptiality. In his model, marriage preference depends only on age and sex, while other dimensions, such as socio-economic status, marital status, and ethnicity, are not considered.

\subsection{Two new simple measures of the marriage squeeze}

In this section, we take Schoen's reasoning as our starting point and describe two measures that operate analogously to his $S$ measure. The underlying idea is that differences in the observed quantum of nuptiality between the two sexes indicate the presence of a marriage squeeze.

Let us start from the observed Proportion Ever Marrying (PEM) for men $\left(P E M^{m}\right)$ and for women $\left(P E M^{f}\right)$, respectively. We can define an index of imbalance, which we call $S^{\prime}$ on the marriage market, as:

$$
S^{\prime}=\frac{P E M^{m}-P E M^{f}}{P E M^{m}+P E M^{f}}
$$

$S^{\prime}$ expresses the difference in the proportion ever marrying in a nuptiality table as a fraction of the sum of the proportions ever marrying in both sexes. This index differs only very slightly from the one proposed by Schoen. It can however be directly computed if one has access only to the proportion ever marrying. We can see that the interpretation is quite similar to Schoen's index:

- when both one-sex populations have the same proportion ever marrying, then $S^{\prime}=0$, and there is no marriage squeeze;

- when male rates yield a proportion ever married higher than that for females, then $S^{\prime}>0$, and there is a marriage squeeze for females; 
- when male rates yield a proportion ever married smaller than that for females, then $S^{\prime}<0$, and there is a marriage squeeze for males.

In addition to $S^{\prime}$, it could be useful to introduce another even simpler, alternative measure of the imbalance between the sexes. Often one has access only to measures based on reduced events (Wunsch and Termote, 1978[51]) instead of occurrence/exposure measures. In the case of marriages, reduced events, are given by the number of marriages at each age divided by the total age-specific population of that sex. The sum of age-specific first marriage rates is the so-called Total Nuptiality Rate $T N R$. Starting from the sexspecific measures $T N R_{m}$ and $T N R_{f}$, which equal to minus the logarithm of $\beta$ and $\gamma$ respectively, we can define a similar index

$$
I=\frac{T N R_{m}-T N R_{f}}{T N R_{m}+T N R_{f}}
$$

The rationale behind $S^{\prime}$ and $I$ is almost identical to that given by $S$ (even though the denominators are still affected by the squeeze experienced by the two populations), but in addition they point to a further simplification of the measure of the marriage squeeze. In particular, $I$ has the advantage of being based solely on the reduced events and, as a consequence, it is not necessary to have access to complete nuptiality tables. This provides us with simple tool for analysing the imbalance between the sexes on the marriage market. Sometimes occurrence/exposure rates for constructing nuptiality tables are not available. In fact, that would require the distribution of the population by marital status, which is not always available in non-censuses years, even in countries with fairly good statistical records. On the other hand, the main disadvantage of our simple indices is that they cannot be connected to measures of the theoretical impact of the marriage squeeze such as Schoen's $R$ and $Q$. 


\section{The dynamics of marriage squeezes in Italy 1969- 1995}

We now apply the above-mentioned measures of the marriage squeeze to Italian nuptiality data from 1969 to 1995 . We use an archive of period, sexand age-specific nuptiality rates built at ISTAT $^{9}$; with this archive we also built annual period nuptiality tables ${ }^{10}$. This allows us to look for the effect of postwar births and migrations.

In Table 1 several indicators of Italian marriage intensity and the marriage market are reported. One can see an increase in the proportion of never married people at age 50 for both sexes - but especially for men (columns 3 and 6 , respectively). The probability that a woman from the 1969 period life table will never marry was $18 \%$; the same probability rose to $42 \%$ by 1995. Men, as well, experienced an increase in the proportion never married from $17 \%$ in 1969 to $44 \%$ in 1995 . In the same table the aggregate measures of the imbalance between the sexes are also computed.

As can be seen in Table 1 as well as in Figure 1, for all indicess $S, S^{\prime}$ and $I$ we have the same pattern, although $S$ seems to emphasise changes more than the other measures. All three measures are negative, thus indicating a disadvantage on the marriage market for men in the period from 1971 to

\footnotetext{
${ }^{9}$ The data base is composed of age-specific first marriage rates from 1969 to 1995 for both sexes and at the regional level. Age-specific first marriage rates express the observed male and female marriage occurrence between age $x$ and $x+n$ over person-years lived by each sex from age $x$ and $x+n$ at time $t$. It is worth noting that the denominator of the rate is the male and female population regardless of their marital status and that both marriages and person-years are obtained from the resident population in each region.

${ }^{10}$ Details concerning the construction of the dataset and the nuptiality tables are given in Fraboni (2000[16]).
} 
Table 1: $P E M, \beta$ and $\gamma$ at age 50 by sex, and measures of the marriage squeeze: 1969-1995 - ITALY

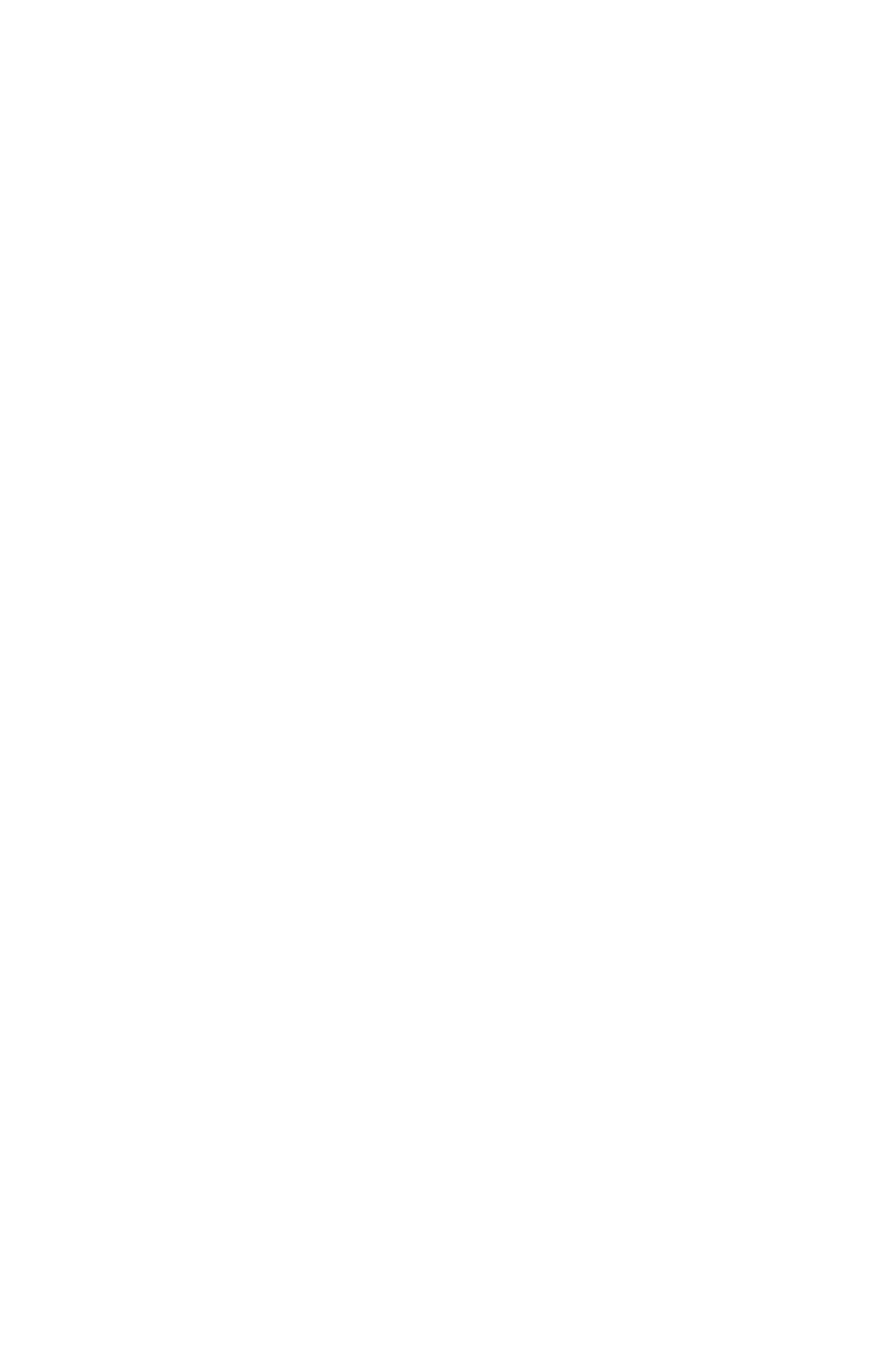


Figure 1: Comparison between birth cohorts size (1940-1981) and squeeze $S, S^{\prime}$ and $I(1969-1995)-I T A L Y$
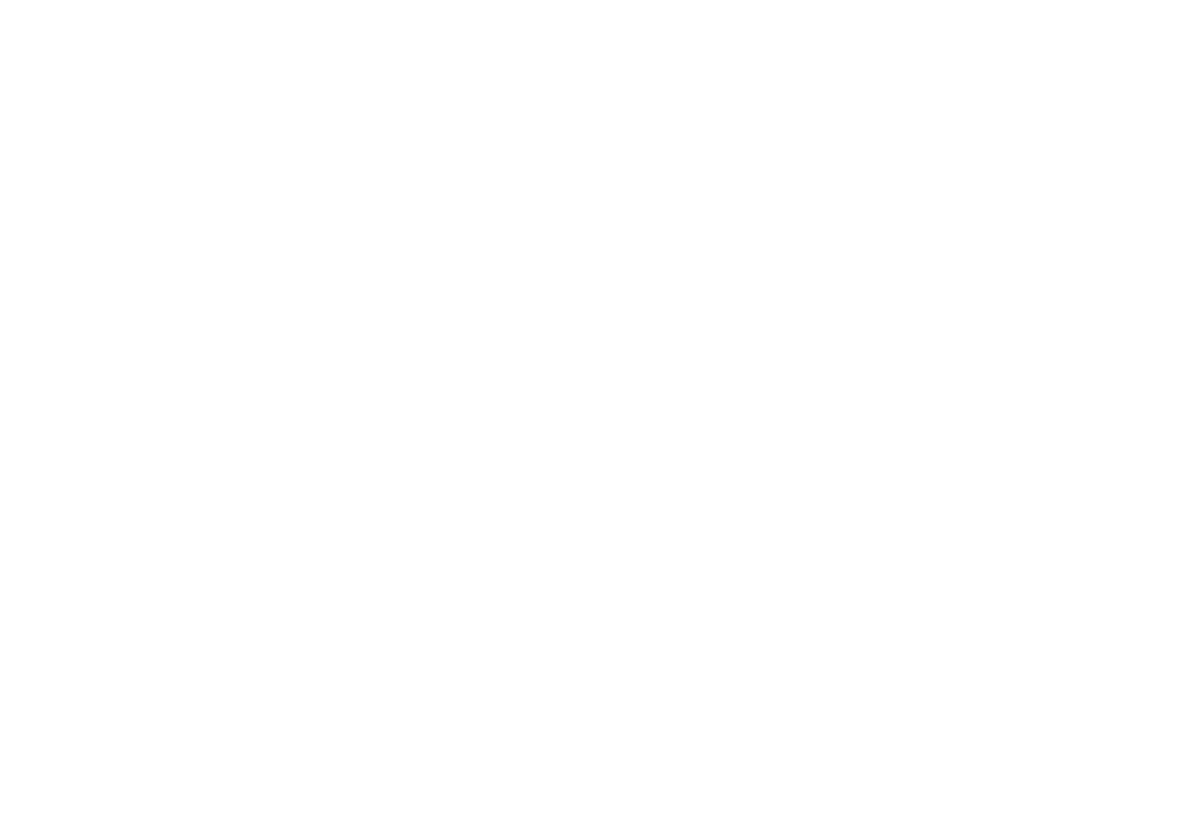

1979, with the lowest level reached in the years 1974-75, and in the period after 1989. On the other hand, the indices show a marriage squeeze against females for the years 1969-1971 and 1979-1989; the highest value is reached in 1984. It seems, then, that the newly proposed indices describe the existing imbalance on the marriage market rather well. The proportion of marriages 'lost' because of the marriage squeeze (here we refer to Schoen's $R$ ) is at a maximum when the squeeze is tightest, regardless of its sign. The highest loss is for the years 1974-75 and 1983-85. More recently, as the squeeze has become tighter, the proportion of lost marriages has also been increasing.

The dynamics of the marriage squeeze are clearly challenging: how can 
we explain such fluctuations? As in US-based studies, we first look at the evolution of births. By plotting the trend in the number of births and the measures of the squeeze together, we can get the idea of how variations in natality are echoed in subsequent imbalances in the marriage market (Figure 1). The basic idea is that women who were born during a period of growth in the number of births were more likely to have trouble in finding a proper match. In contrast, men born during a phase of reduction in the number of births are more likely to find themselves in a squeeze when searching for a partner. The time-scale of the abscissa at the top exhibits a lag of 26 years with respect to the scale at the bottom, given that the average age at marriage over the entire period and including both sexes is 25.7 years. The latter serie (at the bottom) is linked to the annual number of births, while the former (the top) indicates the time scale for the index of imbalance. This can provide us with a broad idea of the delayed effect of the variation in the birth cohorts at approximately the time when the individuals can be expected to get married, that is, at the age of 25 years. The number of births has oscillated significantly over time in Italy. As was the case in many European countries, natality decreased drastically during the Second World War, while the first 5 years after the war showed a marked increase. During the early 1950s the number of births decreased again - down to a total of about 860,000 - and this general level remained constant up to the beginning of the 1960s. In the early 1960s the well-known increase in the birth rates known as the baby-boom occurred. In 1964, 1,016 thousands babies were born in Italy. After that year, births started to decrease steadily - down a level of 526,000 in 1995.

The pattern of the squeeze, as described by the indices $S, S^{\prime}$, and $I$ broadly follows the dynamics of the pattern of births, with the expected lag 
corresponding more or less to the mean age at marriage. Around the years 1973-75, the squeeze is strongly negative: the gap between the male and female probability of ever marrying is about 2 per cent, relative to their joint probability. This can be linked to the recuperation in the number of births that occurred after the Second World War about 25-30 years earlier (19461948). As a consequence of the decline in births that occurred immediately after this post-war catch-up, a marriage squeeze against males showed up when men from these cohorts came of marrying age. They experienced a disadvantage in searching for their partners among the smaller cohorts born a few years later. Similarly, we can observe a strong marriage squeeze against females in the first half of the 1980s. From the mid-1950s to the mid-1960s, there was a slight but steady rise in the absolute numbers of births, which translated into a disadvantage for women of marrying age in the first half of the 1980s. The declining number of births observable just after the baby-boom brings about a strong negative index.

Given the recent steady decline in the number of births in Italy (which is comparable to the decline in some other countries that have reached very low levels in fertility) we can expect to see an even tighter marriage squeeze against men in the near future. This might affect the transition to marriage and, potentially, contribute to a further reduction in fertility.

\section{Regional differences and the role of internal mi- grations}

Trends observed and just described for Italy as a whole may hide rather complex patterns at the regional level. Given the possibilities of our data, we conduct a regional analysis. The idea is that space matters in the marriage 
market. This means that regional migrations influence the marriage squeeze, and this should be reflected in the measures of imbalance between the sexes. We assume that mortality does not really matter in the period under study. Of course, given the level of migratory flows, the interpretation will be much less straightforward than it would be for the national level.

\subsection{Macro-regional patterns}

The overall trends described earlier for Italy as a whole also hold at the macroregional level (Figure 2) ${ }^{11}$. The actual levels do appear to be different, however. Central Italy almost always has a squeeze against women, and it is tighter here than in all other macro-regions of Italy. A squeeze of $S=+0.04$ for the years 1983-1985 in the Centre, for example, means that there is a gap between the male and female probability of ever marrying, relative to their joint probability, of 4 per cent (Figure 2). The same pattern holds true for southern regions, as well (where the highest level reached in the middle of the 1980s is around 0.025), while northern regions experienced an especially tight squeeze for men during the 1970s, the maximum level was $S=-0.03$ in 1974, and, recently, from the end of the 1980s onward. On the whole, it seems that there was a marriage squeeze against men during the 1970s and the early 1990s in northern Italy, whereas in central and southern Italy there was almost always a female disadvantage, which was especially high at the beginning of the 1970s and in the middle of the 1980s (Figure 2).

Let us try to interpret the observed patterns in light of our knowledge of interregional migrations. The North is the richest part of the country. The North-West has always been the industrial power house of Italy, while

\footnotetext{
${ }^{11}$ This analysis has also been conducted using the new indexes of imbalance $S^{\prime}$ and $I$, but to save space we report here only the result regarding Schoen's $S$.
} 
Figure 2: Measure of the Squeeze $I$ in the macroregions: Italy, 1969-1995

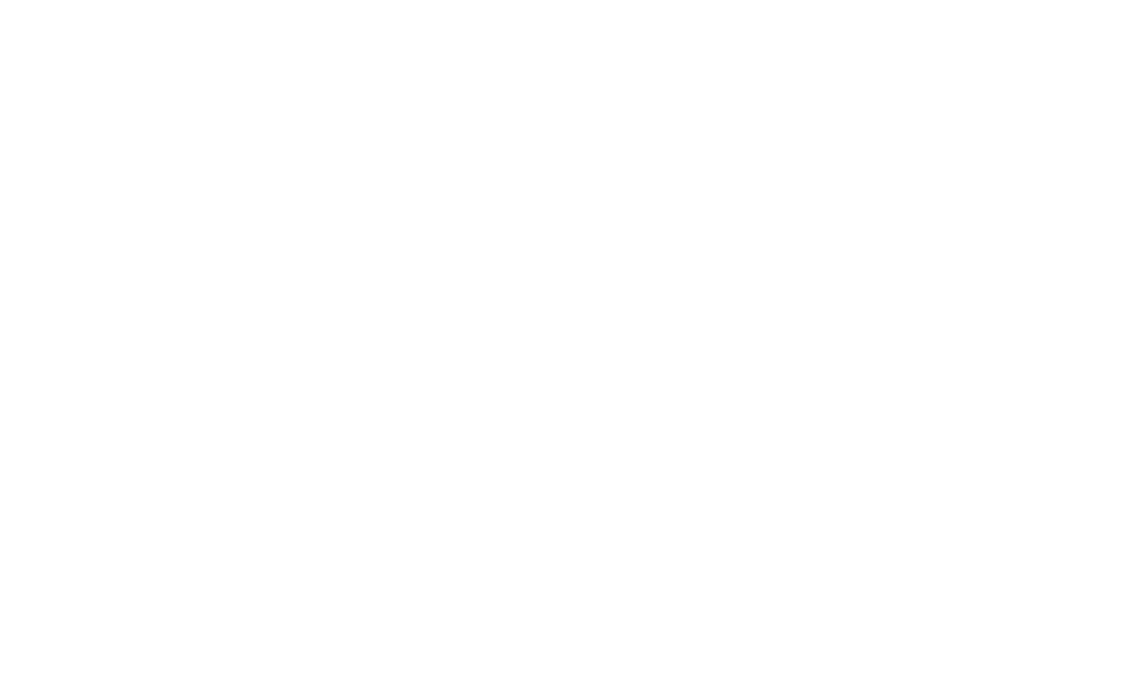

the North-East has seen a more recent industrial boom. The Centre is characterised by a new model of dispersed and small- to medium-scale industrialisation. The South and the Islands are affected by poverty in the interior regions and by economically stagnant coastal towns and cities (Istat, 1998[34]). Throughout the post-war period, the strongest flows have been from South-islands to the North and internally within the North (from North East to North West). Smaller flows have been targeted to the Central region of Lazio (mostly, to Rome) from the southern regions and central and east coast provinces (Golini, 1974[24]).

Migration rates at different geographical scales show that, at least for the comparison between 1955 and 1993, short-distance (province-internal) migration was the most important, and it also declined the least. The secondmost important kind of movement was long-distance migration. Finally, 
medium-distance migration between provinces was less important. By 1993 it had falled to half its 1955 level. Long-distance inter-regional, migration was a constant factor over the period 1955-93. It was characterised by heavy outflows from the South of Italy to the North before 1978 and by smaller outflows after that year (Istat, 1998[34]).

The 1960s, the years of the 'economic boom', saw a great deal of movements across regional boundaries in Italy. Especially southern Italians moved towards the economic triangle (Piedmont, Liguria and Lombardy) and towards northern Europe (especially the Federal Republic of Germany and Switzerland). But the strongest flow was directed towards the North of Italy. Between 1958 and 1963 more than 900,000 people left South Italy (Ginsborg, 1989[17]; Bonifazi et al.1999[5]). South-to-North migration losses are most marked for the young adult ages of labour force entry, between 15 and 29 years (Istat, 1998 [34]).

During the 1970s Italy underwent a trend that had started in the late 1960s, which is characterised by a reduction in both long- and short-distance geographical mobility. This trend, which resulted from both economic and social factors, has been called a 'counter-urbanisation' process. The years 1973-1975 saw a sharp decline in internal migrations, which was associated with the employment effect of the first oil shock (Istat, 1998[34]). Of the Italian regions only Sicily exhibited the opposite behaviour, as the dynamics to and from its towns increased in the 1970s (Micheli, 1988[40]). The 1980s were then characterised by a very low level of inter-regional moment.

If we focus on the trend of the marriage market described by $S$, we notice the existence, over the twenty-five years under study, of a pattern of imbalance between the sexes which can be explained by the internal movement of the Italian population. 
At the regional level, we observe that the general pattern regarding the divisions holds, although some regions exhibit a certain degree of deviations therefrom. Among the central regions, for example, Lazio has particularly striking $^{12}$. It has an extremely high and positive level of $S$ over the entire period, which means that women are subject to a marriage squeeze in general. Thus, there is no simple connection between in- and out-migration and the direction of the squeeze. The South, in contrast, is characterised by two strong, distinct patterns. On the one hand, Sicily and parts of Apulia exhibit a constant, positive level of the imbalance to the disadvantage of women, whereas Calabria, on the other hand, shows a degree of marriage squeeze that increases from a very low level up to a zero, which was reached in the mid-1980s, only to fall again. northern regions have very high $S$ values, which approach one another when negative. Veneto, Liguria, and Piedmont, in particular, are areas where the squeeze against men is particularly tight.

These apparently contradictory results stimulated us to perform a deeper analysis of two neighbouring regions of the South with different marriage market dynamics: Calabria and Sicily.

\subsection{The interesting cases of Calabria and Sicily}

In this section we focus on a dynamic comparison of the marriage squeeze in two regions: Sicily and Calabria (Table 2 and Figure 3). In Sicily there prevails a disadvantage for women in the marriage market ( $I$ is always positive), while in Calabria it is men who are in a worse position over time ( $I$ is almost always negative).

The two neighbouring (and mostly outmigration) regions share very

\footnotetext{
${ }^{12}$ In this region the presence of Rome, Italy's capital, is a relevant factor.
} 
Table 2: Summary of the main indicators for Calabria and Sicily, 1969-1995

\begin{tabular}{|c|c|c|}
\hline \multirow{4}{*}{$\frac{⿱ 亠 䒑}{\frac{U}{\omega}}$} & 总赵 & 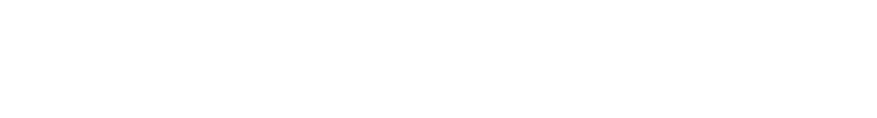 \\
\hline & 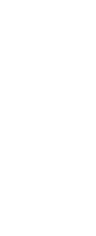 & 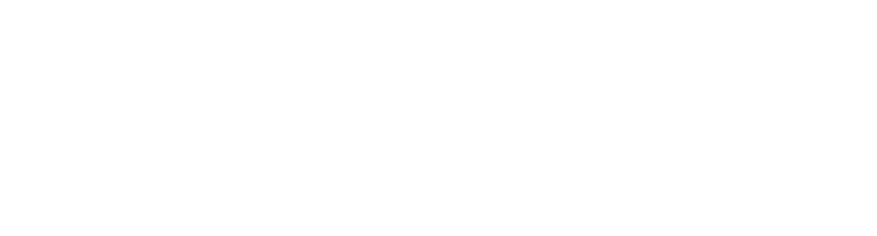 \\
\hline & - & 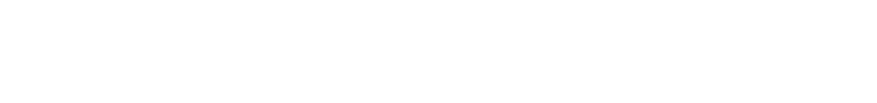 \\
\hline & 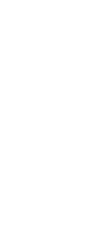 & 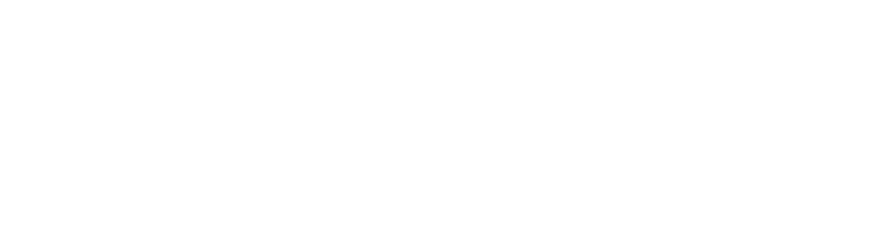 \\
\hline \multirow{4}{*}{ 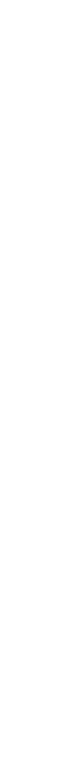 } & 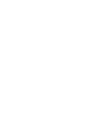 & 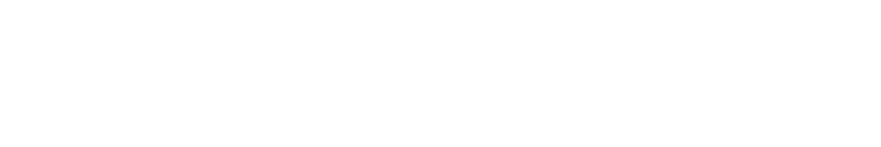 \\
\hline & 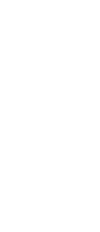 & 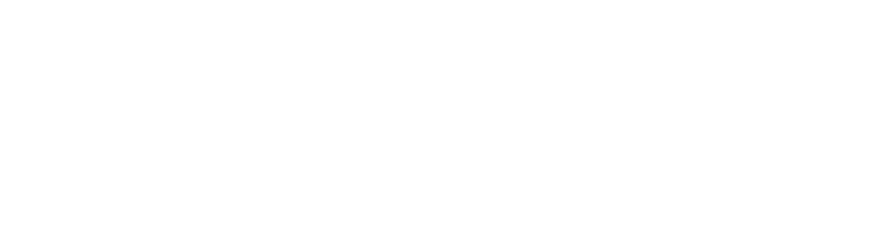 \\
\hline & - & 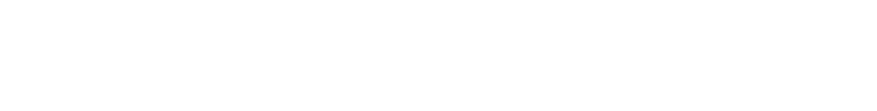 \\
\hline & 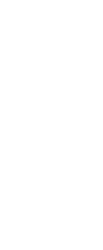 & 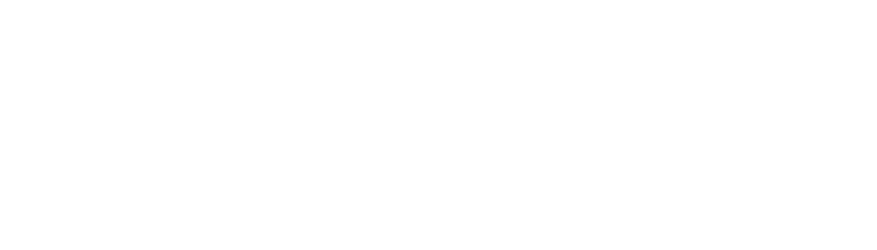 \\
\hline \multicolumn{2}{|c|}{ 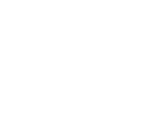 } & 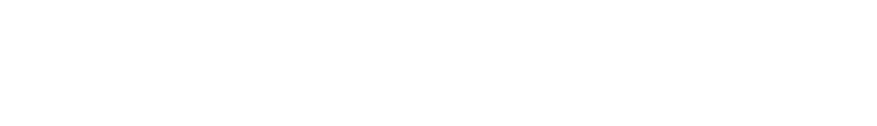 \\
\hline
\end{tabular}


Figure 3: Imbalance in the marriage market measure between Calabria and Sicily, 1969-1995

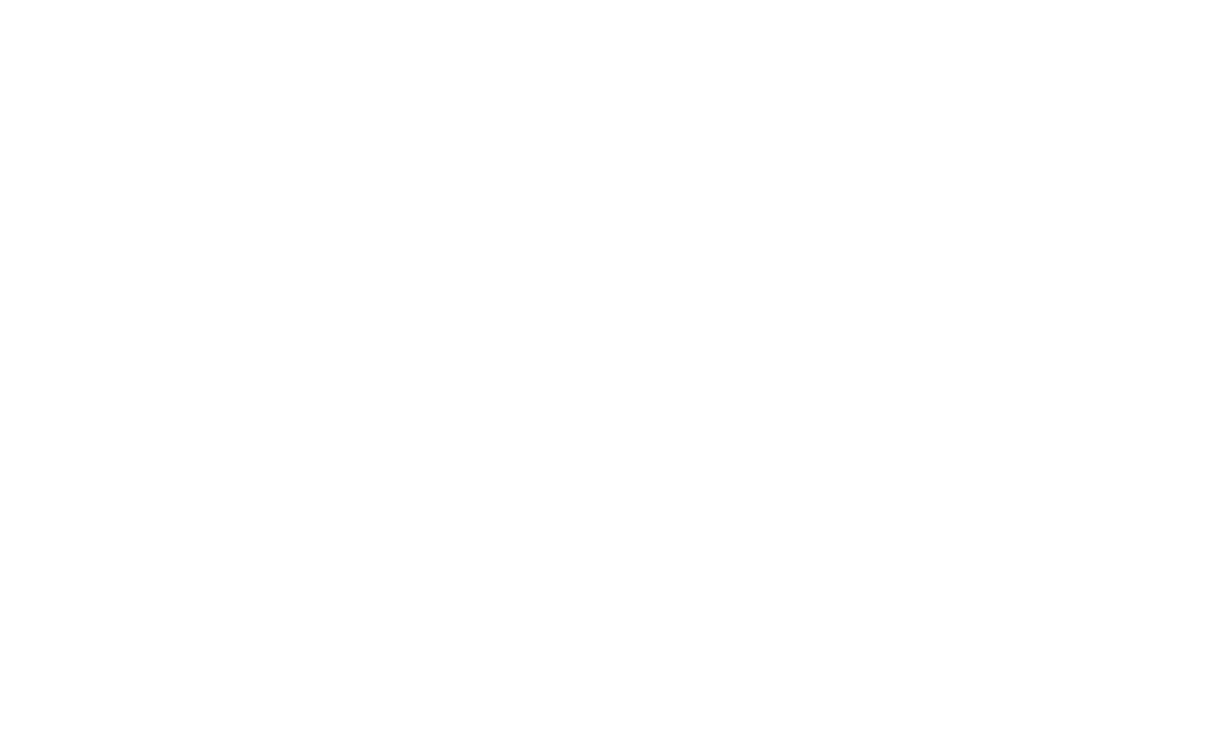

similar fertility trends (Santini, 1997[33]). Since 1940 the birth pattern is characterised by a drop during the Second World War period, which was followed by a "catch-up process" in the second half of the 1940s, and then a slight decline over time. In contrast, the two regions have a very different history of migratory movements, which is highly differentiated between men and women (Table 3). First of all, it must be noted that there are no data available on the inflow and outflow on migratory movements by marital status $^{13}$. It should also be stressed that data regarding place of residence are often affected by quality problems.

\footnotetext{
${ }^{13}$ Nor is the population distribution by marital status available at the regional level, except for in censuses years. Estimates are available for Italy as a whole for the years 1952-1981 (Castiglioni, 1989[10]).
} 
Table 3: Net migrations rates by sex and 5-years age group, for Calabria and Sicily, 1969-1995

\begin{tabular}{|r|rr|rr|}
\hline MEN & \multicolumn{2}{|c|}{ CALABRIA } & \multicolumn{2}{c|}{ SICILY } \\
& MEN & WOMEN & MEN & WOMEN \\
\hline $15-19$ & & & & \\
1955 & -6.94 & -6.92 & -3.21 & -3.28 \\
1960 & -12.66 & -11.69 & -5.57 & -5.45 \\
1965 & -8.66 & -7.13 & -3.15 & -2.31 \\
1970 & -22.46 & -31.45 & -14.63 & -15.83 \\
1975 & -12.25 & -17.61 & -6.16 & -3.82 \\
1980 & -9.28 & -8.77 & -5.91 & -3.17 \\
1985 & -3.07 & -0.68 & -1.28 & -0.09 \\
$20-24$ & & & & \\
1955 & -20.41 & -16.73 & -10.82 & -8.06 \\
1960 & -37.93 & -29.89 & -20.28 & -14.12 \\
1965 & -25.83 & -18.25 & -13.78 & -8.31 \\
1970 & -42.24 & -44.36 & -23.74 & -20.63 \\
1975 & -24.58 & -20.43 & -11.83 & -5.49 \\
1980 & -21.22 & -17.97 & -13.53 & -6.45 \\
1985 & -12.57 & -7.33 & -10.60 & -4.22 \\
$25-29$ & & & & \\
1955 & -19.76 & -16.11 & -10.22 & -7.55 \\
1960 & -35.62 & -29.39 & -18.26 & -13.45 \\
1965 & -21.46 & -17.03 & -10.06 & -7.01 \\
1970 & -32.55 & -25.80 & -23.69 & -15.46 \\
1975 & -10.45 & -6.55 & -6.23 & -1.20 \\
1980 & -15.56 & -10.78 & -8.81 & -4.97 \\
1985 & -8.59 & -5.88 & -8.57 & -3.44 \\
\hline \hline
\end{tabular}


Since we do not have the possibility to check internal movements of the population by sex, age, and marital status, we can only give some hypotheses of interpretation. First, some general remarks on the migration differentials. Calabria has had higher outmigration than Sicily. Inflow rates are low in both regions and show no significant differences between men and women. Except for in the age group 15-19 male and female out-migration movements are almost identical in both regions. Women from Calabria in the 20-24 age group had an outmigration rate comparable to that of men, particularly since 1970, while women from Sicily always had a outmigration rates considerably lower than that of men (Table 3). The year 1972 was characterised by a very high level of migration, especially in comparison with the following period, when internal movements declined significantly due to the oil shock.

Our attempt to disentangle the components contributing to the observed imbalance starts from the years where the highest marriage imbalances are registered. We then attempt to understand the changes in the annual mean ages of men and women and the size of the cohort to which they mainly belong.

In particular, we select some of the years where the two regions show a particularly high (positive or negative) imbalance in marriage market conditions. Figure 3 shows the imbalances for the two regions, measured by the $I$ index over the years 1969 and 1995. In Sicily in 1972, the Total First Marriage Rate 1084.6 first marriages for men is and 1045.7 for women. This means that the imbalance in the marriage market is positive. The actual figure is 0.0182 (Table 2 and Figure 4). The year 1972 is also characterised by one of the lowest differences in the mean age at marriage of men and women: 3.9 years. Men, who married at an average age of 27, belong on average to the 1945 birth cohort, while women, who married at an average 
Figure 4: Comparison between birth cohort size and imbalance $I$ - SICILY

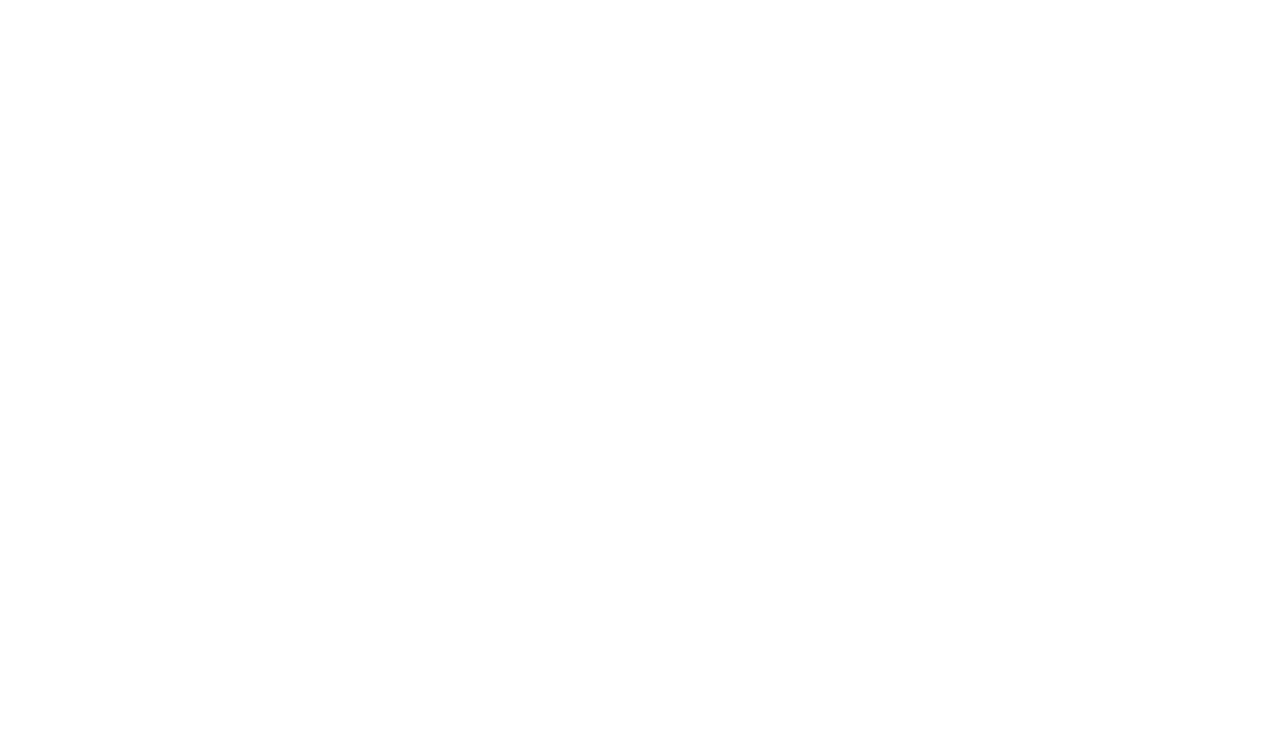

Figure 5: Comparison between birth cohort size and imbalance $I$ - CALABRIA

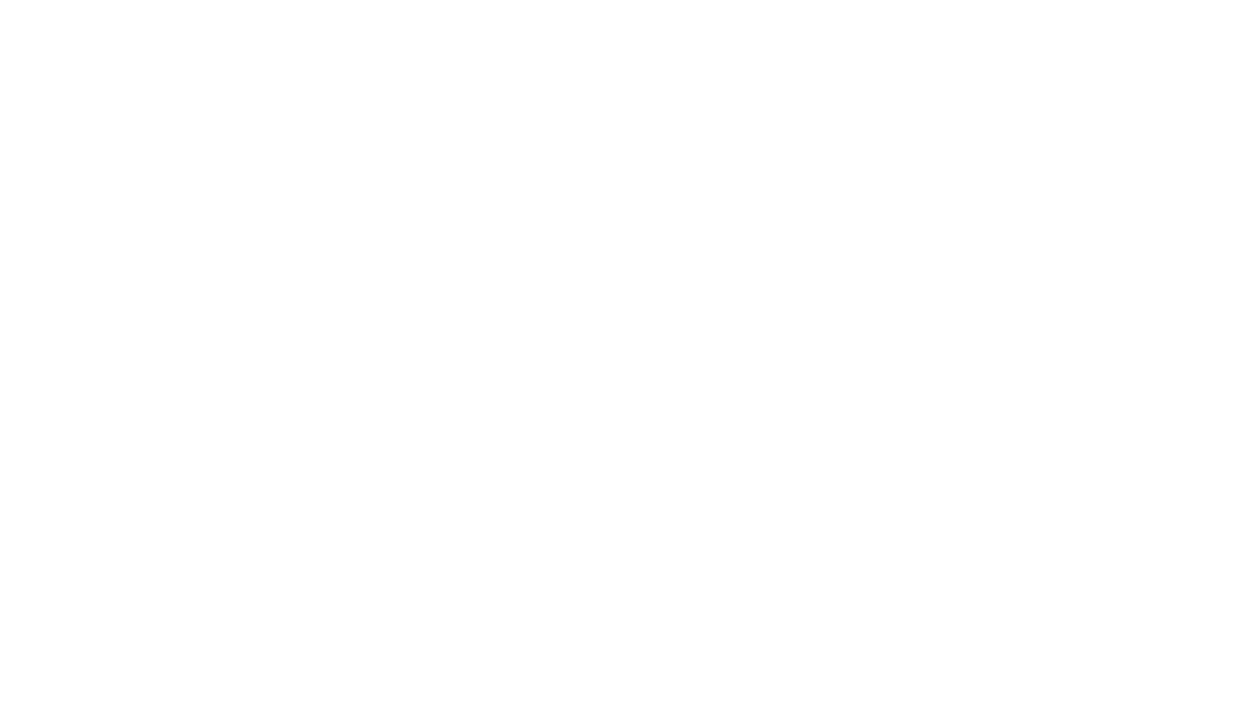


age of 23.1, belong on average to the cohort born in 1949. Because of the exceptionally low natality during the Second World War, men born up to 1945 were looking for brides among the large pool of post-war baby-boomers. Moreover, the male advantage on the marriage market can also be seen in the slight shifts in period-specific age at marriage. When compared to previous years, the male mean age in 1972 is in a phase of slight decrease while that of women is rising. Furthermore, the positive situation for men was accentuated by the fact that women did not migrate with the same intensity as men did. The low mobility of women in Sicily put them in a very disadvantageous position with respect to marriage. In a nutshell, in 1972 Sicily the male advantage in the marriage market is essentially the outcome of the differential sizes of cohorts.

In comparison, it is striking to see that the sign of the squeeze in Calabria is always to the disadvantage of men. And this although Calabria shared the same declining birth pattern as Sicily (and Italy as a whole) during the war and the same rise in birth rates afterwards. We assume then that differential migratory movements between sexes have played a key role (Table 3). It is worth noting that the net migration rates for the women in Calabria after 1970 are higher than they are for men in the age groups 15-19 and 20-24. Of course, we do not know the marital status of these young migrant women, but since they left at such young ages, we can assume that the majority of them were unmarried at the time of their move (or that they moved to marry a partner they had already met). The pool of eligible women was thus diminished. This improved the chance for young women to get married while it caused a marriage squeeze for the men. The high level of migration of young women can be assumed to be the main reason for men's disadvantage in Calabria in 1972 and surrounding years. 
In 1979 there was still imbalance in Sicily to the disadvantage of women, although an equilibrium had almost been reached. Here the key to interpreting the situation is the slight postponement in the age at marriage of women born around 1955-56 (who had a mean age at marriage of 23.2 years) and of men born around 1952 (who had a mean age at marriage of 26.8 years), together with the slight decline in births that occurred in the early 1950s and the ensuing rise in the second half of that decade. In 1979, in fact, the difference between the mean ages at marriage, just 3.6 years, is again one of the lowest observed for this region ${ }^{14}$.

To arrive at an adequate interpretation of the imbalance in Sicily in 1983 one needs to include some further factors. The imbalance in favour of men is fairly high in that year $(I=0.0264)$, and the mean age at marriage is around 27 for men and 23 for the women, with a precise difference of 3.7 years. The natality component does not contribute very much to clarifying the situation. The 27 year-old grooms belong on average to the cohort born in 1956 and the 23 year-old brides were born on average in 1959-60. In the late 1950s there was a slight increase in births in Sicily, which may have been partly responsible for a female disadvantage. Furthermore, analysing the age pattern of nuptiality rates for some selected years, we notice that in Sicily (and, with less emphasis, also in other southern regions) there was a sudden increase in the rate of marriage for 18-year-olds (Figure 6). A new law concerning the minimum age at marriage came into effect in

\footnotetext{
${ }^{14}$ It should also be noted that it is not necessarily a noticeable reverse in timing that takes place to compensate for an imbalance in the cohort sizes among which men and women choose their partners. It is often just a slight increase in the mean age of those in the unfavourable position as well as a slight decline in the age of those in the more favourable position that can compensate for the outcome (Schoen, 1983 [45]).
} 
1975, which can help us to understand this phenomenon. According to the new law, the minimum age at marriage was set at 18 for both men and women ${ }^{15}$. In Sicily, where the timing of marriage had been particularly early for women, the introduction of this law turned out to have an abrupt delaying effect on the behaviour of potential brides. The proportion of those who marry at 18 years is extraordinarily high starting with the cohort of women born in 1957 (Figure 6). This age effect can be largely attributed to the institutional change. The postponement of entry into first union for this birth cohort further increased the disadvantage of women, who were already in an unfavourable position due to their low mobility.

Lastly, Calabria as depicted in 1983 observes a more balanced marriage market, as the Total First Marriage Rates for men and women have almost the same level: 731.6 first marriages for men and 736.4 for women. The mean age is about 27 years for men and 23 for women, with a difference of slightly over 4 years. Here the cohorts involved are mainly men born in 1955-56 and women born in 1960. It should also be noted that the left-skewed bell-shaped pattern for Calabria in 1983 is characterised by a fork between ages 18 and 20 for women in the 1960 cohort and between age 18 and 26 years for men in the 1950 and 1955 cohort (Figure 6). Here again we can imagine that the reduction in the level of out-migration, which also meant a greater degree of similarity between the sexes than in Sicily, together with the changes in the timing of marriage (a slight decline in mean age for men and a slight rise in the mean age for women) ended up balancing the marriage market.

From the comparative analysis of Calabria and Sicily, we notice that the effect of fluctuations in natality and of migratory movements (together with

\footnotetext{
${ }^{15}$ Some exceptions allowing people to marry at younger ages were and are still allowed but only through a judge's ruling.
} 
Figure 6: Age pattern of nuptiality rates by sex and birth cohorts, for Calabria and Sicily
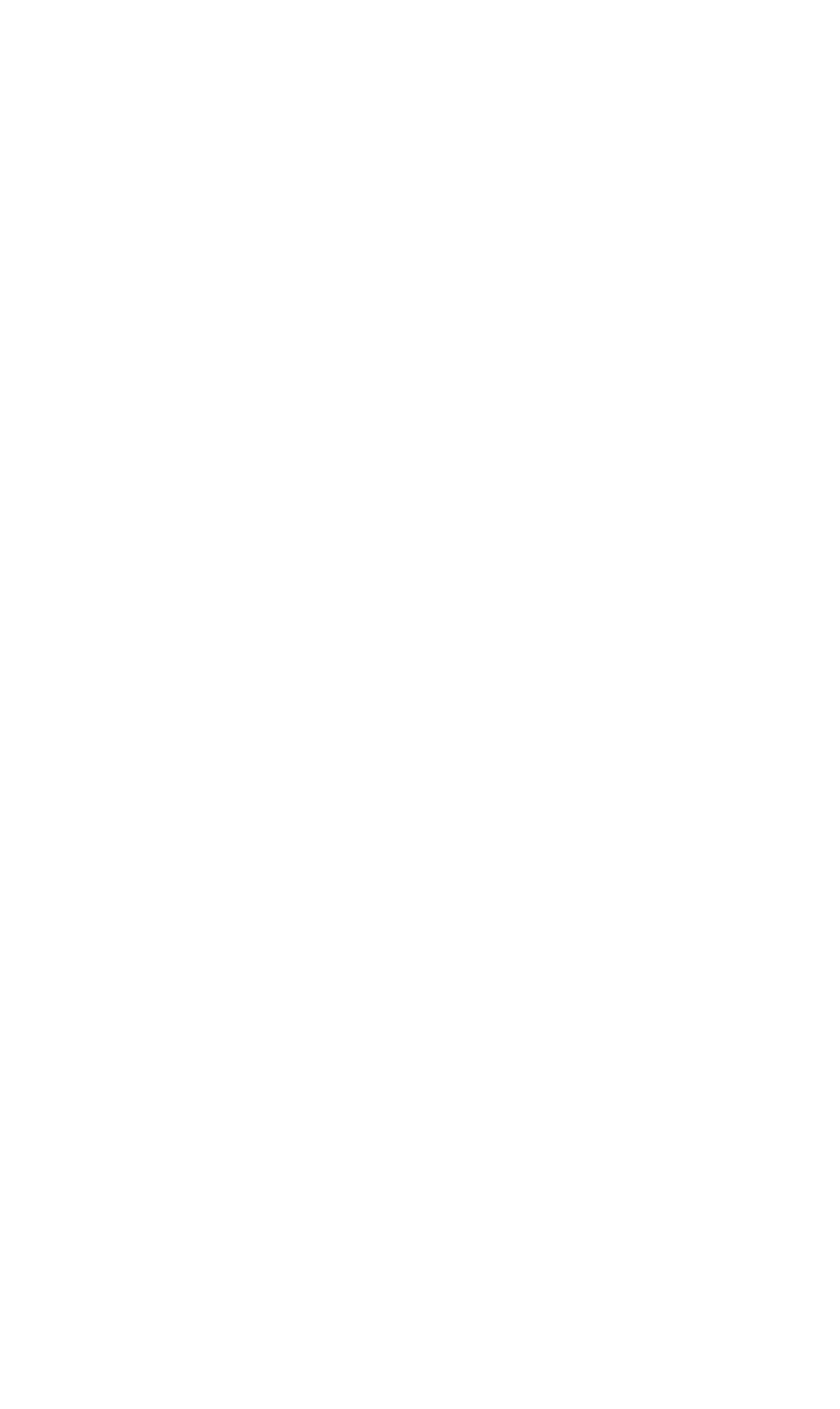
the sex differentials in migrations) have been highly intertwined in shaping the marital chances at the regional level. We also have some evidence that the legal change concerning the minimum age at marriage played a relevant role.

\section{Conclusion}

In this paper, we studied the marriage market from a dynamic perspective. The Italian case is particularly interesting due to the strong fluctuations of the post-war period, from baby boom to baby bust. The measures proposed in the literature arising from two-sex demography, in particular Schoen's index, together with other simple alternatives such as our measures based on reduced events, allowed us to trace the dynamics of the marriage squeeze and to compare it to the evolution of births at the national level.

Our main finding is that there is an imbalance on the Italian marriage market that stems from siginificant variations in the number of births. Some cohorts of women find themselves in a marriage squeeze (basically the 1980s) while other cohorts of men, especially those born after the post-war rise in births or after the baby-boom, face this same unfavourable situation. The squeeze was particularly strong for women in the Centre and the South of Italy in the early 1970s and the 1980s, while the same was true for men, especially in the North, during the 1970s and since the beginning of the 1990s.

In addition, we showed that migration, especially differential migration by sex, had a crucial role in determining the extent of the marriage squeeze at a regional level. The cases of Calabria and Sicily showed that migratory patterns matter. Some evidence was also found for an influence of the insti- 
tutional setting, namely the legal norms determining the minimum age at marriage.

Our findings are particularly important in light of current developments in the number of births in Italy (and, most likely, in other European countries as well). They show that, if there is no influence of migration, a marriage squeeze against men can be expected for the coming decades. Immigration may change this, of course, depending on the sex composition of the migrants. In any case, it seems that a marriage squeeze resulting from a decline in births might itself be the cause of a subsequent decline in births, especially in those countries where marriage is still crucial for reproduction.

\section{Acknowledgements}

We acknowledge ISTAT for having allowed us to access the data used in this paper. We thank Viviana Egidi, Arnstein Aassve and Karl Brehmer for comments, and Robert Schoen for an useful discussion. Views or opinions expressed in this papers are attributable to authors and do not necessarily reflect those of the Max Planck Institute for Demographic Research.

\section{References}

[1] Donald S. Akers. On measuring the marriage squeeze. Demography, 4(2):907-924, 1967.

[2] Gary S. Becker. A theory of marriage, pages 299-344. 1974.

[3] Gary S. Becker. A treatise on the Family. Harvard University Press, Cambridge, 1981. 
[4] Alberto Bonaguidi (ed.). Prospettive metodologiche nello studio della mobilità della popolazione. Incontro di studio, Pisa, 13-14 ottobre 1988, Dipartimento di Statistica e Matematica Applicata all'Economia, Università di Pisa. Pacini, Pisa, 1990.

[5] Corrado Bonifazi, Angela Chieppa, and Frank Heins. Le migrazioni interne meridionali: un'analisi a livello provinciale, chapter 11, pages 53-95. Volume 10/99 of Monografie [6], 1999.

[6] Corrado Bonifazi (ed). Mezzogiorno e migrazioni interne, volume 10/99 of Monografie. IRP-CNR, Roma, 1999.

[7] Michel Bozon. Apparence physique et choix du conjoint, pages 91-110. 1991.

[8] Michel Bozon and Françoise Heran. La découverte du conjoint. II: les scénes de rencontre dans l'espace social. Population, (1):121-150, 1988.

[9] J.C. Caldwell, P.H. Reddy, and Pat Caldwell. The causes of marriage change in South India. Population Studies, (37):343-361, 1983.

[10] Maria Castiglioni. Una ricostruzione della popolazione residente in Italia per sesso, età e stato civile, 1952-1981. Istituto di Ricerche sulla Popolazione - IRP, Roma, 1989.

[11] Luciano Ciucci and Filomena Racioppi (eds.). Studi di popolazione. Nuovi approcci per la descrizione e l'interpretazione. Convegno dei Giovani Studiosi dei Problemi di Popolazione. Dipartimento di Scienze Demografiche, Università degli studi di Roma"La Sapienza", Roma, 1994, Roma, 2-4 giugno 1993. 
[12] John Dagsvik. Aggregation in matching markets. Discussion paper, Statistics Norway, Oslo, 1998.

[13] Kingsley Davis (ed.). Contemporary Marriage: comparative perspective on a changing institution. Russel Sage Foundation, New York, 1985.

[14] Alessandra De Rose and Cesidia Rufo. Il mercato matrimoiale in Italia. Evoluzione della popolazione coniugabile e dei fattori di selezione della coppia, pages 41-71. In Convegno dei Giovani Studiosi dei Problemi di Popolazione [11], 1994.

[15] Paolo De Sandre, Fausta Ongaro, Rosella Rettaroli, and Silvana Salvini. Matrimonio e figli: tra rinvio e rinuncia. Studi e Ricerche. Il Mulino, Bologna, 1997.

[16] Romina Fraboni. Marriage market and homogamy in Italy: an event history approach. Phd in demography, University of Rome 'La Sapienza', Rome, December 2000.

[17] Paul Ginsborg. Il 'miracolo economico', chapter 7, pages 283-343. In [18], 1989.

[18] Paul Ginsborg. Storia d'Italia dal dopoguerra ad oggi. Einaudi, Torino, 1989.

[19] Alain Girard. Le choix du conjoint: une enquête psycho-sociologique en France, volume Cahier n.70 of Travaux et Documents. INED-PUF, Paris, third edition, 1981.

[20] D.V. Glass. Population in History: Essay in Historical Demography. Eversley D.E.C., London, 1965. 
[21] Paul C. Glick. Fifty years of family demography: a record of social change. Journal of Marriage and the Family, (50):861-873, November 1988.

[22] Paul C. Glick, David M. Herr, and John C. Bersford. Family formation and family composition: trends and prospects, pages 30-40. In [50], second edition, 1963.

[23] Noreen Goldman, Charles F. Westoff, and Charles Hammerslough. Demography of the marriage market in the United States. Population Index, (50):5-25, 1984.

[24] Antonio Golini. Distribuzione della popolazione, migrazioni interne e urbanizzazione in Italia. Istituto di Demografia, Rome, 1974.

[25] Margaret E. Greene and Vijayendra Rao. The marriage squeeze and the rise in informal marriage in Brazil. Social Biology, 42(1-2):65-82, 1995.

[26] Amyra Grossard-Shechtman. Marriage Squeezes and the Marriage Market, chapter 14, pages 375-395. In [13], 1985.

[27] J. Hajnal. European marriage patterns in perspective, chapter 6, pages 101-143. In [20], 1965.

[28] Louis Henry. Nuptiality. Theoretical population biology, (3):135-152, 1972 .

[29] Louis Henry. Naissance d'une population de couples mariés, pages 8196. Volume 1-2 of [35], 1973. 
[30] David M. Herr and Amyra Grossbard-Shechtman. The impact of the female marriage squeeze and the contraceptive revolution on the sex roles and the women's liberation movement in the United States, 1960 to 1975. Journal of Marriage and the Family, February 1981.

[31] Jan M. Hoem. Concepts of a bisexual theory of marriage formation. Statistisk Tidskrift, (4):295-300, 1969.

[32] ISTAT. La fecondità delle regioni italiane. Analisi per coorti. Anni 19952-1993. Number 35 in Informazioni. Istat, Roma, 1997.

[33] ISTAT. Tavole di fecondità regionale. In Informazioni [32], 1997.

[34] ISTAT. Internal migration and regional population dynamics in italy. Essays, n.3, 1998.

[35] IUSSP. International Population conference, volume 1-2. Liege, 1973.

[36] Nico Keilman. Demographic and discrete-choice two-sex marriage models. paper presented at the workshop on Non-Linear Demography, Rostock, Germany, May 1998, April 1998.

[37] K.C. Land and A. Rogers (eds.). Multidimensional Mathematical Demography. Academic Press, USA, 1982.

[38] Peter McDonald. L'équilibre numérique entre hommes et femmes et le marché matrimonial. Population, pages 1579-1590, 1995.

[39] D.D. McFarland. Models of marrigae formation and fertility. Social Forces, (54):66-83, 1975.

[40] Giuseppe A. Micheli. Città, circolazione, permanenza: ancora sulle implicazioni teoriche e operative del concetto di mobilità, chapter I, pages 
17-37. In Incontro di studio, Pisa, 13-14 ottobre 1988, Dipartimento di Statistica e Matematica Applicata all'Economia, Università di Pisa [4], 1990.

[41] H.V. Muhsam. The marriage squeeze. Demography, 11(2):291-299, May 1974.

[42] John Pollard. Modelling human populations for projections purposessome of the problems and challenges. Australian Journal of Statistics, (2):63-76, 1975 .

[43] Robert Schoen. The armonic mean as the basis of a realistic two-sex marriage model. Demography, 18(2):201-216, May 1981.

[44] Robert Schoen. Generalizing the Life Table Model to incorporate interactions between the sexes, chapter 7, pages 385-443. In [37], 1982.

[45] Robert Schoen. Measuring the tightness of a marriage squeeze. Demography, 20(1):61-78, February 1983.

[46] Robert Schoen. The Marriage Squeeze, chapter 8, pages 167-185. In The Plenum Series on Demographic Methods and Population Analysis [47], 1988.

[47] Robert Schoen. Modeling Multigroup Populations. The Plenum Series on Demographic Methods and Population Analysis. Plenum Press, New York, 1988.

[48] Scott J. South and Kim M. Lloyd. Marriage markets and nonmarital fertility in the United States. Demography, 29(2):247-264, May 1992. 
[49] Scott J. South and Kim M. Lloyd. Spousal alternatives and marital dissolution. American Sociological Review, 60:21-35, February 1995.

[50] Marvin B. Sussman (ed.). Sourcebook in marriage and the family. Houghton Mifflin, Boston, second edition, 1963.

[51] Guillame J. Wunsch and Marc G. Termote. Introduction to Demographic Analysis. Principles and Methods. Plenum Press, New York, London, 1978. 